\title{
PENGARUH EQUITY TO TOTAL ASSETS RATIO, NON PERFORMING RATIO \\ DAN FINANCING TO DEPOSIT RATIO TERHADAP KINERJA KEUANGAN KOPERASI BMT NURUL JANNAH GRESIK TAHUN 2012-2014')
}

\author{
Febby Karina Anastasia \\ Mahasiswa Program Studi Ekonomi Islam-Fakultas Ekonomi dan Bisnis-Universitas Airlangga \\ Email: febby53@gmail.com \\ Dina Fitrisia Septiarini \\ Departemen Ekonomi Syariah-Fakultas Ekonomi dan Bisnis-Universitas Airlangga \\ Email: dina.fitrisia@gmail.com
}

\begin{abstract}
:
This research aimed to know the influence of Equity to Total Assets Ratio, Non Performing Ratio and Financing to Deposit Ratio to Return on Assets Ratio in BMT Nurul Jannah Gresik. This research used the quantitative approach method. The analysis technique used multiple linear regression.

Based on the result of t-test, Equity to Total Assets Ratio and Financing to Deposit Ratio partially did not influence significantly to Return on Assets Ratio, but Non Performing Financing influenced significantly to Return on Assets Ratio. The result of simultaneous test showed that Equity to Total Assets Ratio, Non Performing Ratio and Financing to Deposit Ratio had significant effect to Return on Assets Ratio with siginificant value 0,001. The ability of Equity to Total Assets Ratio, Non Performing Ratio and Financing to Deposit Ratio in explaining Return on Assets Ratio of 38,3\% and the remaining 61,7\% was explained by other variables outside the model.
\end{abstract}

Keywords: Equity to Assets Ratio, Non Performing Financing, Financing to Deposit Ratio, Return on Assets

\section{PENDAHULUAN}

\section{Latar Belakang}

Director International Islamic Law and Finance Centre Singapore Management University yang bernama Andrew White menilai Indonesia adalah pemimpin dalam pengaplikasian Lembaga Kevangan Mikro Syariah (LKMS) atau yang dikenal dengan Baitul Maal Wattamwil (BMT) (Hapsari, 2013). Menurut Sholihin (2010:174), "Baitul Maal Wattamwil adalah lembaga keuangan mikro yang dioperasikan dengan prinsip bagi hasil, menumbuhkembangkan bisnis usaha mikro dalam rangka mengangkat derajat dan martabat serta membela kepentingan kaum fakir miskin, ditumbuhkan atas prakarsa dan modal awal dari tokoh-tokoh masyarakat setempat dengan berlandaskan pada sistem ekonomi yang salaam : keselamatan (berintikan keadilan), kedamaian dan kesejahteraan."

Salah satu Baitul Maal Wattamwil (BMT) di Gresik yaitu Koperasi BMT Nurul Jannah. Lembaga tersebut mendapatkan akta pendirian dari Departemen Koperasi Pengusaha Kecil dan Menengah Kabupaten Gresik dengan No. 489/BH/KWK.13/VII/98 dengan nama Koperasi Baitul Maal Wattamwil Nurul Jannah. Selain itu dengan dikeluarkannya Undang-undang Pengelolaan Zakat No. 38 tahun 1999 dan peraturan

\footnotetext{
1) Jurnal ini merupakan bagian dari skripsi yang ditulis oleh (Febby Karina Anastasia:041114128) yang diuji pada 3 Agustus 2015
} 
pelaksanaannya dengan Keputusan

Menteri Agama Republik Indonesia No. 581 tahun 1999, maka Koperasi BMT Nurul Jannah telah mendapatkan Surat Keputusan dari Bupati Gresik No. 450/3436/HK/403.14/2002 tentang pengukuhan Koperasi BMT Nurul Jannah sebagai Lembaga Amil Zakat (LAZ).

Sudarsono (2003:8) menyatakan bahwa "Baitul Maal Wattamwil didirikan dengan maksud untuk memfasilitasi masyarakat bawah yang tidak terjangkau oleh pelayanan bank syariah atau BPR syariah". Selain itu, BMT tidak hanya memberikan pembiayaan kepada para UMKM, namun BMT memberikan pula pembinaan, seperti yang dilakukan oleh Koperasi BMT Nurul Jannah yang memberikan pembinaan baik berupa mental spiritual Islam maupun pembinaan manajemen usaha.

Baitul Maal Wattamwil sebagai lembaga penghubung antara pihak yang kelebihan dana dengan pihak yang kekurangan dana harus bisa menyalurkan pembiayaannya dengan baik dan tepat. Oleh karena itu BMT harus mempunyai kinerja keuangan yang baik. Kinerja keuangan dapat diukur dengan analisis rasio. Perhitungan rasio untuk menilai posisi kinerja suatu bank, akan memberikan gambaran yang jelas tentang baik atau tidaknya operasional suatu bank, yang dilihat dari posisi keuangannya dalam neraca dan laba-rugi (Faisol, 2007). Pengukuran kinerja keuangan perlu dilakukan pada tiap akhir periode tertentu, hal ini merupakan salah satu tindakan penting yang harus dilakukan oleh Koperasi guna mengetahui prestasi dan keuntungan yang dicapainya (Afandi, 2014:2). Rasio yang digunakan untuk mengukur kinerja keuangan yaitu Return on Assets (ROA).

Return On Assets merupakan rasio profitabilitas. Rasio ini juga sering disebut Return On Investment (ROI) (Gill dan Chaton, 2005:52). Return on Investment pada koperasi menggambarkan kemampuan koperasi menghasilkan Sisa Hasil Usaha (SHU) melalui aset yang dimiliki koperasi. Return on Investment yang maksimal akan memberikan dampak positif bagi keberlangsungan koperasi, sehingga kesejahteraan anggota koperasi dapat tercapai (Candraeni, 2013:3).

Equity to Total Assets Ratio (EAR) menunjukkan prosentase investasi dalam total aktiva yang telah dibelanjai dengan dana yang berasal dari modal sendiri (Jumingan, 2009:135). Tinggi rendahnya rasio ini akan mencerminkan pengelolaan modal sendiri perusahaan. Semakin tinggi Equity to Total Assets Ratio maka akan semakin rendah kebutuhan pendanaan eksternal yang diperlukan, begitu pula tingkat beban bunga akan rendah yang pada akhirnya berdampak pada peningkatan laba (Candraeni, 2013:5).

Non Performing Financing pada bank dan perusahaan konvensional disebut Non Performing Loan (NPL). Rasio ini membandingkan antara total kredit yang bermasalah dengan total kredit yang 
diberikan kepada debitur. Non Performing Financing merupakan rasio pembiayaan bermasalah dalam perbankan syariah (Wibowo, 2013). Semakin tinggi rasio NPF akan menyebabkan hilangnya kesempatan dalam memperoleh pendapatan dari pembiayaan yang diberikan. Hal tersebut akan mempengaruhi perolehan laba, sehingga akan berpengaruh buruk pada ROA (Wibowo, 2013).

Sholihin (2010:277) mengatakan bahwa "Financing to Deposit Ratio (FDR) adalah perbandingan pembiayaan yang diberikan oleh bank dengan dana pihak ketiga yang berhasil dikerahkan oleh bank". Semakin tinggi rasio LDR menunjukkan tingginya dana yang telah disalurkan dibandingkan dengan dana pihak ketiga yang berada di bank. Jadi semakin besar rasio LDR, mengakibatkan semakin besar pendapatan kredit yang diterima bank. Hal ini akan berdampak terhadap semakin tingginya rasio ROA (Manikam, 2013:3).

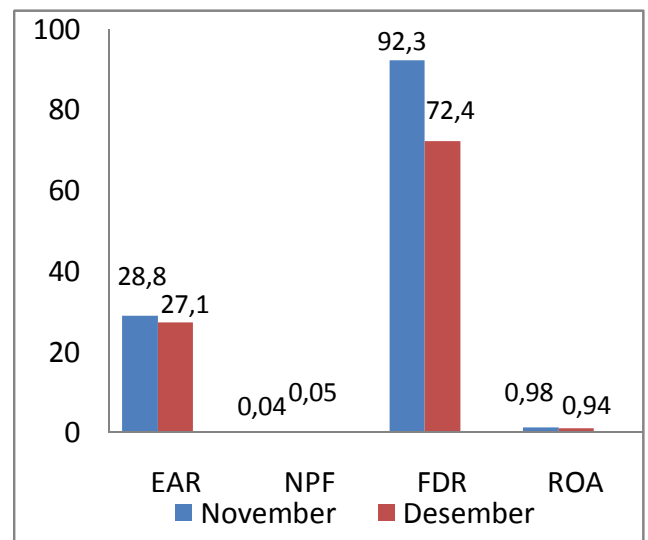

Sumber : Koperasi BMT Nurul Jannah Grafik 1

Perkembangan EAR, NPF, FDR dan ROA pada Koperasi BMT Nurul Jannah Gresik Bulan November dan Desember 2012 (dalam persen)

Grafik 1.1 menunjukkan perbandingan antara EAR, NPF, FDR dan ROA pada Koperasi BMT Nurul Jannah Bulan November dan Desember 2012. Equity to Total Assets ratio Koperasi BMT Nurul Jannah pada Bulan November 2012 sebesar 28,8\% dan pada Bulan Desember 2012 menjadi 27,1\%. Sehingga EAR pada Bulan Desember 2012 menurun apabila dibandingkan dengan Bulan November 2012. Non Performing Financing pada Bulan November 2012 sebesar $0,04 \%$ dan pada Bulan Desember 2012 mengalami kenaikan sebesar $0,01 \%$ sehingga menjadi $0,05 \%$. Keadaan NPF yang mengalami kenaikan tersebut berbanding terbalik dengan FDR yang mengalami penurunan drastis pada Bulan Desember 2012. Financing to Deposit Ratio pada Bulan November 2012 sebesar $92,3 \%$ dan pada Bulan Desember 2012 menurun sebesar $19,9 \%$ sehingga menjadi $72,4 \%$. Return on Assets Koperasi BMT Nurul Jannah mengalami penurunan, yang awalnya $0,98 \%$ menjadi $0,94 \%$.

Berdasarkan latar belakang masalah diatas, ternyata aspek EAR, NPF dan FDR mempunyai peran dalam ROA. Oleh karena itu peneliti tertarik untuk melakukan penelitian yang berjudul "Pengaruh Equity to Total Assets Ratio, Non Performing Financing dan Financing to Deposit Ratio terhadap Kinerja Kevangan pada Koperasi BMT Nurul Jannah Tahun 2012-2014." 


\section{Rumusan Masalah}

Berdasarkan uraian latar belakang di atas, maka rumusan masalah yang dapat diajukan pada penelitian ini adalah:

1. Apakah Equity to Total Assets Ratio, Non Performing Financing dan Financing to Deposit Ratio secara simultan berpengaruh terhadap Return on Assets pada Koperasi BMT Nurul Jannah?

2. Apakah Equity to Total Assets Ratio berpengaruh terhadap Return on Assets pada Koperasi BMT Nurul Jannah?

3. Apakah Non Performing Financing berpengaruh terhadap Return on Assets pada Koperasi BMT Nurul Jannah?

4. Apakah Financing to Deposit ratio berpengaruh terhadap Return on Assets pada Koperasi BMT Nurul Jannah?

\section{Tujuan Penelitian}

Berdasarkan uraian latar belakang dan rumusan masalah diatas, maka tujuan penelitian ini adalah:

1. Mengetahui pengaruh Equity to Total Assets Ratio, Non Performing Financing dan Financing to Deposit Ratio secara simultan terhadap Return on Assets pada Koperasi BMT Nurul Jannah.

2. Mengetahui pengaruh dari Equity to Total Assets Ratio terhadap Return on Assets pada Koperasi BMT Nurul Jannah.
3. Mengetahui pengaruh dari Non Performing Financing terhadap Return on Assets pada Koperasi BMT Nurul Jannah.

4. Mengetahui pengaruh dari Financing to Deposit ratio terhadap Return on Assets pada Koperasi BMT Nurul Jannah.

\section{LANDASAN PUSTAKA}

Kinerja keuangan dari BMT yaitu BMT mampu melakukan penggalangan, pengaturan, penyaluran dan penempatan dana dengan baik, teliti, hati-hati, cerdik dan benar sehingga arus pendanaan dalam pengelolaan kegiatan usaha BMT akan menjadi lancar. Kelancaran tersebut akan mempunyai dampak yang berkelanjutan bagi peningkatan keuntungan BMT (Sholihin, 2010:176).

Analisis rasio kinerja keuangan bank digunakan untuk mengetahui kinerja suatu bank (Leon dan Ericson, 2007:118). Kinerja keuangan koperasi juga seperti bank yaitu diadopsi dari rasio-rasio kevangan yang disesuaikan dengan kondisi Koperasi. Pengukuran kinerja keuangan perlu dilakukan pada tiap akhir periode tertentu, dan pengukuran ini merupakan salah satu tindakan penting yang harus dilakukan oleh Koperasi guna mengetahui prestasi dan keuntungan yang dicapainya (Afandi, 2014:2).

Equity to Total Assets Ratio adalah rasio yang membandingkan antara modal sendiri dengan seluruh aset yang dimiliki dikalikan dengan 100\%. Menurut Kurnia 
(2012), "EAR merupakan indikator finansial yang digunakan untuk mengukur keterikatan atau motivasi dari pemilik atas kelangsungan usaha dari bank. Rasio ini menunjukkan besarnya modal sendiri yang digunakan untuk mendanai seluruh aktiva perusahaan". Rasio EAR digunakan untuk mengukur kemampuan keuangan atau solvency jangka panjang (Jumingan, 2009:136).

Tinggi rendahnya rasio EAR akan mencerminkan pengelolaan modal sendiri perusahaan. Semakin tinggi equity to total assets ratio maka akan semakin rendah kebutuhan pendanaan eksternal yang diperlukan, begitu pula tingkat beban bunga akan rendah yang pada akhirnya berdampak pada peningkatan laba (Candraeni, 2013:5). Hendrayanti (2013) mengatakan bahwa EAR berpengaruh signifikan terhadap ROA.

Non Performing Financing membandingkan antara total pembiayaan yang bermasalah dengan seluruh jumlah pembiayaan yang diberikan kepada debitur (Rafelia dan Ardiyanto, 2013). Semakin tinggi rasio NPF menunjukkan kualitas pembiayaan bank syariah semakin buruk. Bertambahnya NPF akan mengakibatkan hilangnya kesempatan untuk memperoleh pendapatan dari pembiayaan yang diberikan sehingga mempengaruhi perolehan laba dan berpengaruh buruk bagi ROA (Wibowo, 2013).

Tingginya rasio NPF menandakan bank tidak bisa mengelola pembiayaannya dengan baik karena semakin besar pula kegagalan pengembalian oleh debitur. Hal ini akan mengakibatkan kerugian karena profitabilitas yang diperoleh bank akan menurun. Apabila profitabilitas menurun, maka ROA juga ikut menurun. Sehingga Rasio Non Performing Loan (NPL) memiliki pengaruh signifikan negatif terhadap ROA (Manikam, 2013:3).

Sholihin (2010:277) mengatakan bahwa "Financing to Deposit Ratio (FDR) adalah perbandingan pembiayaan yang diberikan oleh bank dengan dana pihak ketiga yang berhasil dikerahkan oleh bank".

Ketentuan Bank Indonesia untuk FDR adalah $80 \%$ hingga $110 \%$. Apabila rasio FDR kurang dari $80 \%$ menunjukkan bahwa bank masih belum bisa menjalankan fungsi intermediasinya antara pihak yang kelebihan dan kekurangan dana dengan baik. Jika rasio FDR lebih dari $110 \%$ berarti total pembiayaan yang diberikan melebihi dana yang dihimpunnya. Oleh karena vang yang dihimpun bank sedikit, maka bank masih belum bisa menjalankan fungsinya dengan baik pula. (Suryani, 2011:13).

"Imbal hasil atas aset atau Return on Assets (ROA) merupakan rasio laba sebelum dipotong pajak dibandingkan dengan total aset dikalikan 100 (Leon dan Ericson, 2007:109). Pada koperasi, keuntungan yang diperoleh disebut sebagai Sisa Hasil Usaha (SHU) (Sitio dan Tamba, 2001:28). Laba sebelum pajak didefinisikan oleh UU No. : 
35.3/Per/M.KUKM/X/2007 sebagai Sisa Hasil Usaha (SHU) sebelum nisbah, zakat dan pajak.

Financing to Deposit Ratio
membandingkan
pembiayaan dengan total dana pihak ketiga. Semakin tinggi FDR menandakan bahwa semakin tinggi pula dana atau pembiayaan yang disalurkan kepada masyarakat dibanding dengan dana pihak ketiga yang berada di bank (Suryani, 2011:13). Tingkat penghasilan dari pembiayaan yang disalurkan merupakan tingkat penghasilan tertinggi bagi bank. Sehingga apabila semakin banyak pembiayaan yang disalurkan maka semakin banyak pula penghasilan yang akan didapat oleh bank (Muhammad, 2002:238).

Hipotesis penelitian ini yaitu EAR, NPF dan FDR secara simultan berpengaruh signifikan terhadap ROA pada Koperasi BMT Nurul Jannah, EAR berpengaruh signifikan terhadap ROA pada Koperasi BMT Nurul Jannah, NPF berpengaruh signifikan terhadap ROA pada Koperasi BMT Nurul Jannah dan FDR berpengaruh signifikan terhadap ROA pada Koperasi BMT Nurul Jannah.

Model analisis yang digunakan terdiri dari dua, model analisis hubungan simultan dan paersial. Model analisisnya dapat di formulasikan sebagai berikut:

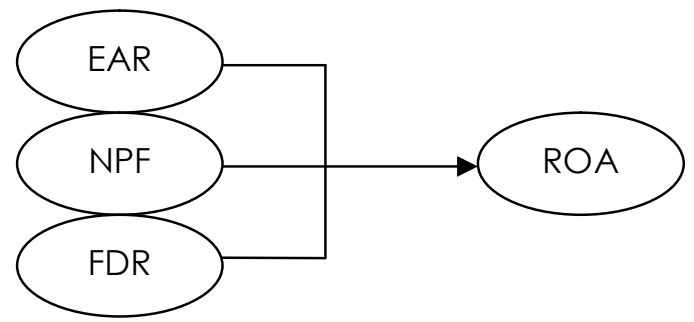

Sumber : Penulis

Gambar 1.

Model Analisis Hubungan Simultan

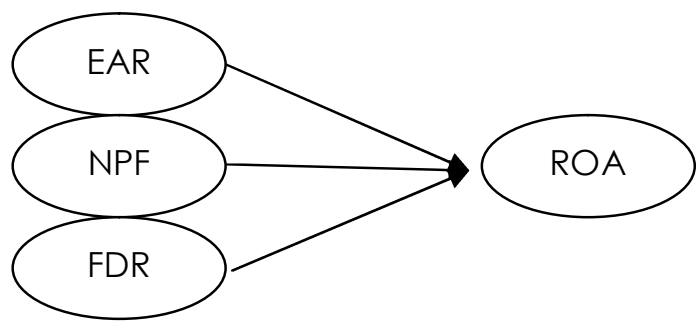

Sumber : Penulis

Gambar 2.

Model Analisis Hubungan Parsial

Persamaan yang digunakan dalam penelitian ini adalah :

$$
\begin{array}{ll}
Y=a+ & \beta_{1} X_{1}+\beta_{2} X_{2}+\beta_{3} X_{3}+e_{i} \ldots \ldots \ldots . . . .(1) \\
Y & =\text { Return on Assets (ROA) } \\
X_{1} \quad & =\text { Equity to Asset Ratio (EAR) } \\
X_{2} \quad=\text { Non Performing Financing (NPF) } \\
X_{3} \quad=\text { Financing to Deposit Ratio (FDR) } \\
\beta_{1} \beta_{2} \beta_{3}=\text { Koefisien regresi } \\
a \quad=\text { intercept } \\
e_{i} \quad=\text { Variabel pengganggu }
\end{array}
$$

\section{METODE PENELITIAN}

\section{Pendekatan Penelitian}

Pendekatan penelitian yang digunakan dalam penelitian ini adalah pendekatan kuantitatif. Menurut Hermawan (2005:18) "Penelitian kuantitatif adalah suatu pendekatan penelitian yang bersifat obyektif, mencakup pengumpulan dan analisis data kuantitatif serta menggunakan metode pengujian statistik". Penelitian ini menggunakan pendekatan kuantitatif karena memerlukan perhitungan yang sistematis. Penghitungan sistematis tersebut digunakan untuk mengukur hubungan antar variabel. Pengukuran tersebut 
menggunakan alat statistik sehingga menghasilkan kesimpulan yang dapat digeneralisasikan.

\section{Identifikasi Variabel}

Variabel yang digunakan dalam penelitian ini dibedakan menjadi 2 jenis, yaitu:

\section{Variabel Independen}

"Variabel independen merupakan variabel stimulus atau variabel yang mempengaruhi variabel lain" (Soegoto, 2008:55). Dalam penelitian ini variabel independen yang digunakan yaitu Equity to Total Assets Ratio (EAR), Non Performing Financing (NPF) dan Financing to Deposit Ratio (FDR).

2.Variabel Dependen

"Variabel dependen adalah variabel yang memberikan reaksi/respons jika dihubungkan dengan variabel independen" (Soegoto, 2008:55). Variabel dependen yang digunakan dalam penelitian ini yaitu Return on Assets (ROA).

\section{Definisi Operasional Variabel}

Definisi operasional variabel-variabel yang digunakan dalam penelitian ini adalah:

1. Equity to Total Assets Ratio (EAR) Equity to Total Asset Ratio adalah rasio yang membandingkan antara modal sendiri atau ekuitas dengan seluruh aset yang dimiliki dikalikan dengan 100\%. Data EAR yang berasal dari laporan keuangan bulanan Koperasi BMT Nurul Jannah tahun 2012-2014 ini merupakan data rasio.

$$
\text { EAR }=\frac{\text { Modal Sendiri }}{\text { Total Aktiva }}
$$

2. Non Performing Financing (NPF)

Non Performing Financing adalah rasio yang membandingkan antara pembiayaan bermasalah dengan total pembiayaan. Data NPF yang berasal dari laporan keuangan bulanan Koperasi BMT Nurul Jannah tahun 2012-2014 ini merupakan data rasio.

$$
\text { NPF }=\frac{\text { Pembiayaan Bermasalahx } 100 \% \text {.... (2) }}{\text { Jumlah Pembiayaan }}
$$

3. Financing to Deposit Ratio (FDR)

Financing to Deposit Ratio adalah rasio yang membandingkan antara pembiayaan yang diberikan dengan dana pihak ketiga yang diterima. Data FDR yang berasal dari laporan bulanan Koperasi BMT Nurul Jannah tahun 20122014 ini merupakan data rasio. FDR $=$ Pembiayaan $\times 100 \%$

DPK

4. Return on Assets Ratio (ROA)

Return on Assets adalah rasio yang membandingkan antara laba sebelum dikurang pajak dengan total aset yang dimiliki dikalikan dengan 100 persen. Data ROA yang berasal dari laporan keuangan bulanan Koperasi BMT Nurul Jannah tahun 2012-2014 ini merupakan data rasio. Pada KJKS dan UJKS Koperasi, laba sebelum pajak analog dengan Sisa Hasil Usaha (SHU) sebelum nisbah, pajak dan zakat.

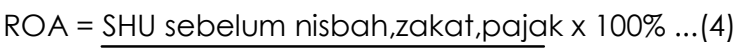
Total aset

\section{Jenis dan Sumber Data}


Data yang digunakan dalam penelitian ini adalah data sekunder. Data sekunder dari penelitian ini berupa rasio keuangan EAR, NPF, FDR serta ROA. Rasio tersebut di dapat dari laporan kevangan bulanan Koperasi Baitul Maal Wattamwil Nurul Jannah pada tahun 2012 - 2014.

Jenis data pada penelitian ini yaitu time series. Time series atau data berkala adalah data yang dikumpulkan dari waktu ke waktu (Supranto, 2000:10). Penelitian ini mengamati satu subyek yaitu Koperasi BMT Nurul Jannah yang diamati dari waktu ke waktu mulai tahun 2012 2014.

\section{Populasi dan Sampel}

"Populasi adalah keseluruhan obyek atau individu yang akan diteliti; memiliki karakteristik tertentu, jelas dan lengkap" (Arifin, 2008:69). Populasi dalam penelitian ini adalah seluruh laporan keuangan Koperasi Baitul Maal Wattamwil Nurul Jannah sejak berdirinya yaitu tahun 1997 hingga 2014.

"Sampel adalah bagian dari populasi yang dipilih melalui cara tertentu yang mewakili karakteristik tertentu, jelas dan lengkap yang dianggap mewakili populasi" (Arifin, 2008:69). Sampel yang digunakan dalam penelitian ini yaitu laporan keuangan bulanan tahun 2012 2014.

\section{Metode Pengambilan Sampel}

Penelitian ini menggunakan Purposive Sampling. Purposive sampling adalah metode pengambilan sampling dengan pertimbangan tertentu.
Kriteria yang digunakan dalam pengambilan sampel pada penelitian yaitu :

1. Laporan keuangan bulanan. Hal ini agar memenuhi persyaratan minimal kebutuhan pengelolaan data. Penelitian ini meneliti tahun 2012-2014, hal ini dikarenakan pada tahun tersebut pertumbuhan ekonomi sedang menurun (Sipendik Team, 2014).

2. Ketersediaan dan kecukupan data. Hal ini agar memenuhi persyaratan minimal kebutuhan pengelolaan data.

\section{Teknik Analisis}

Teknik analisis yang digunakan pada penelitian ini adalah regresi linier berganda. Metode yang digunakan yaitu Ordinary Least Square (OLS). Terdapat beberapa asumsi pada metode OLS yang harus dipenuhi agar hasilnya menjadi BLUE (Best Linier Unbiased Estimator).

\section{HASIL DAN PEMBAHASAN}

\section{Uji Normalitas}

Tujuan dari uji normalitas adalah untuk mengetahui apakah distribusi sebuah data mengikuti atau mendekati distribusi normal, yakni distribusi data dengan bentuk lonceng (bell shaped)(Santoso, 2010:43).

Cara untuk mendeteksi uji normalitas ini adalah dengan grafik dan melihat besaran Komogorov-Smimov. Dasar pengambilan keputusan uji apabila signifikansi dari masing-masing variabel 
lebih dari 0,05 maka data berdistribusi normal (Sujarweni, 2014:55).

Tabel 1.

Uji Normalitas

One-Sample Kolmogorov-Smirnov Test

\begin{tabular}{|c|c|}
\hline Variable & $\begin{array}{c}\text { Asymp. Sig. (2- } \\
\text { tailed) }\end{array}$ \\
\hline EAR &, 115 \\
\hline NPF &, 799 \\
\hline FDR &, 779 \\
\hline ROA &, 790 \\
\hline
\end{tabular}

Sumber: Hasil Uji SPSS 20

Tabel 1 menunjukkan hasil uji normalitas menggunakan One sample Kolmogorovsmirnov. Nilai Asymp. Sig.(2-tailed) masingmasing variabel sebesar $0,115,0,799,0,779$ dan 0,790. Nilai signifikan keempat variabel tersebut lebih besar dari 0,05, maka dapat disimpulkan bahwa terdistribusi normal.

\section{Uji Multikolinearitas}

Tujuan dilakukannya uji multikolinearitas yaitu untuk melihat apakah variabelvariabel bebas berkorelasi atau tidak. Apabila variabel bebas tersebut berkorelasi satu sama lain maka dikatakan terjadi multikolinearitas (Supranto, $2001: 277)$.

Multikolinearitas dapat dilihat melalui nilai VIF dan Tolerance. Dasar acuan atau kriteria pengambilan keputusan dapat disimpulkan jika nilai tolerance $>0,10$ dan nilai VIF antara 1-10, maka dapat disimpulkan bahwa tidak ada multikolinearitas antar variabel independen dalam model regresi (Sujarweni, 2014:185).

Tabel 2.

Uji Multikolinearitas

\begin{tabular}{|c|c|c|c|c|}
\hline $\begin{array}{c}\text { Variabel } \\
\text { Indepen- } \\
\text { den }\end{array}$ & $\begin{array}{c}\text { Nilai } \\
\text { VIF }\end{array}$ & $\begin{array}{c}\text { Nilai } \\
\text { Toleranc } \\
\text { e }\end{array}$ & $\begin{array}{c}\text { Interpretasi } \\
\text { Hasil }\end{array}$ & $\begin{array}{c}\text { Keteran- } \\
\text { gan }\end{array}$ \\
\hline
\end{tabular}

\begin{tabular}{|c|c|c|c|c|}
\hline EAR & 1,279 & 0,782 & $\begin{array}{c}\text { Nilai } \\
\text { tolerance } \\
>0,10 \\
\text { Nilai VIF 1- } \\
10\end{array}$ & $\begin{array}{c}\text { Tidak } \\
\text { terjadi } \\
\text { multikoli- } \\
\text { nearitas }\end{array}$ \\
\hline NPF & 1,608 & 0,622 & $\begin{array}{c}\text { Nilai } \\
\text { tolerance } \\
>0,10 \\
\text { Nilai VIF 1- } \\
10\end{array}$ & $\begin{array}{c}\text { Tidak } \\
\text { terjadi } \\
\text { multikoli- } \\
\text { nearitas }\end{array}$ \\
\hline FDR & 1,821 & 0,549 & $\begin{array}{c}\text { Nilai } \\
\text { tolerance } \\
>0,10\end{array}$ & $\begin{array}{c}\text { Tidak } \\
\text { terjadi } \\
\text { multikol- } \\
\text { inearitas }\end{array}$ \\
& & & $\begin{array}{c}\text { Nilai VIF 1- } \\
10\end{array}$ & \\
\hline
\end{tabular}

Sumber : Hasil uji SPSS 20

Berdasarkan Tabel 2 uji multikoinearitas, nilai tolerance dari masing-masing variabel nilainya lebih dari 0,10 dan VIF berada diantara 1-10 sehingga variabel independen penelitian ini terbebas dari masalah multikolinearitas.

\section{Uji Heteroskedastisitas}

Uji heteroskedastisitas pada penelitian ini menggunakan Uji Spearman. Uji Spearman merupakan ukuran asosiasi yang menuntut kedua variabel diukur sekurang-kurangnya dalam skala ordinal sehingga obyek-obyek atau individuindividu yang dipelajari dapat dalam dua rangkaian berurut (Siegel, 1986:250).

Tabel 3 merupakan hasil dari uji heteroskedastisitas. Pada Unstandardized Residual, nilai Sig. (2-tailed) variabel EAR sebesar 0,592, nilai Sig. (2-tailed) variabel NPF sebesar 0,545, nilai Sig. (2-tailed) variabel FDR sebesar 0,707. Nilai Sig. (2tailed) ketiga variabel tersebut diatas 0,05 sehingga tidak terjadi heteroskedastisitas.

Tabel 3.

Uji Heteroskedastisitas

\begin{tabular}{|l|l|}
\hline \multicolumn{1}{|c|}{ Variable } & \multicolumn{1}{|c|}{$\begin{array}{c}\text { Unstandardized } \\
\text { Residual } \\
\text { Sig. (2-tailed) }\end{array}$} \\
\hline EAR & 0,592 \\
\hline NPF & 0,545 \\
\hline
\end{tabular}


\begin{tabular}{|l|l}
\hline FDR & 0,707
\end{tabular}

Sumber : Hasil uji SPSS 20

Uji Autokorelasi

Tujuan autokolinearitas untuk mengetahui ada tidaknya korelasi antara variabel pengganggu pada periode tertentu dengan periode sebelumnya. Cara mendeteksi adanya masalah autokolinearitas pada data yaitu melalui nilai Durbin Watson (DW). Bila nilai DW terletak diantara batas atas atau upper bound (du) dan (4-du) maka koefisien autokorelasi $=0$, hal ini menandakan tidak ada autokorelasi pada variabel pengganggu periode tertentu dan periode sebelumnya (Sujarweni, 2014:186).

Tabel 4.

Uji Autokorelasi Durbin Watson

\begin{tabular}{|c|c|c|c|}
\hline Nilai & Nilai & Interpretasi & Keterangan \\
Durbin- & $\begin{array}{c}\text { DU } \\
\text { Watson } \\
\text { dan } \\
\end{array}$ & Hasil & \\
& $\mathrm{DL}$ & & \\
\hline 2,282 & $\mathrm{dL}=$ & $\mathrm{du}<\mathrm{DW}<$ & Tidak terjadi \\
& 1,2953 & $4-\mathrm{dU}$ & Autokorelasi \\
& $\mathrm{dU}=$ & & \\
& 1,6539 & & \\
\hline
\end{tabular}

Sumber: Hasil uji SPSS 20

Tabel 4 menunjukkan hasil dari uji autokolinearitas. Berdasarkan tabel DW, nilai upper bound (dU) sebesar 1,6539 sedangkan lower bound (dL) sebesar 1,2953. Nilai DW tersebut harus berada diantara du dan 4-du. Nilai dU yaitu 1,6539 sedangkan nilai 4-dU yaitu 2,3461. Jadi nilai DW sebesar 2,282 berada diantar 1,6539 dan 2,3461. Sehingga tidak terdapat masalah autokolinearitas.

\section{Analisis Regresi Linier Berganda}

Hasil pengolahan data dalam analisis regresi linier berganda dilakukan dengan menggunakan SPSS Statistics version 20. Model yang terbentuk dari regresi linier berganda adalah :

ROA $=1,5-0,008$ EAR - 7,38 NPF - 0,00035 FDR...(5) Interpretasi dari persamaan 5 sebagai berikut :

a. Nilai konstanta sebesar 1,5. Apabila variabel EAR, NPF dan FDR dianggap konstan, maka nilai $Y$ atau ROA sebesar 1,5.

b. Nilai koefisien regresi EAR yaitu -0,008. Apabila variabel NPF dan FDR konstan, maka kenaikan sebesar satusatuan EAR akan menyebabkan penurunan terhadap ROA sebesar 0,008 satuan.

c. Nilai koefisien regresi NPF yaitu -7,38. Apabila variabel EAR dan FDR konstan, maka kenaikan sebesar satusatuan NPF akan menyebabkan penurunan terhadap ROA sebesar 7,38 satuan.

d. Nilai koefisien regresi FDR yaitu 0,00035 . Apabila variabel EAR dan NPF konstan, maka kenaikan sebesar satu-satuan FDR akan menyebabkan ROA turun sebesar -0,00035 satuan.

\section{Pengujian Hipotesis}

Pengujian hipotesis dilakukan agar dapat menginterpretasikan hasil regresi dengan benar. Pengujian hipotesis dilakukan secara simultan dengan menggunakan uji $F$, serta secara parsial dengan menggunakan uji t.

Uji F

Uji $F$ ini bertujuan untuk melihat pengaruh secara menyeluruh dari 
variabel-variabel bebas atau independen terhadap variabel dependen (Atmaja, 2009:1 13). Hipotesis dari uji $F$ ini adalah :

$H_{0}=\beta_{1}=\beta_{2}=\beta_{3}=0$, artinya tidak ada pengaruh secara signifikan dari variabel bebas secara bersama-sama.

$H_{1}=\beta_{1} \neq \beta_{2} \neq \beta_{3} \neq 0$, artinya ada pengaruh secara signifikan dari variabel bebas secara bersama-sama.

Kriteria pengambilan keputusan yaitu apabila signifikansi $<5 \%$ maka $\mathrm{H}_{0}$ ditolak dan bila signifikansi $>5 \%$ maka $\mathrm{H}_{0}$ diterima. Kesimpulan yang didapat $\mathrm{H}_{0}$ ditolak, maka perlu dilakukan uji $t$, namun bila $H_{0}$ diterima maka tidak perlu dilakukan uji $t$.

Tabel 5.

Uji $\mathrm{F}$

\begin{tabular}{|c|c|c|c|}
\hline $\begin{array}{c}\text { Tingkat } \\
\text { Signifikansi }\end{array}$ & A & $\begin{array}{c}\text { Pengujian } \\
\text { Hipotesis }\end{array}$ & Interpretasi \\
\hline 0,001 & 0,05 & $\begin{array}{c}0,001< \\
0,05\end{array}$ & Ho ditolak \\
\hline
\end{tabular}

Sumber : Hasil SPSS 20

Hasil uji $F$ pada Tabel 5 maka dapat dinyatakan bahwa $\mathrm{H}_{0}$ ditolak karena nilai signifikansinya $<0,05$ sehingga dapat disimpulkan bahwa EAR, NPF dan FDR secara simultan berpengaruh signifikan terhadap ROA pada Koperasi BMT Nurul Jannah Gresik.

\section{Uji $\uparrow$}

Uji $\dagger$ ini digunakan untuk menguji variabel-variabel independen secara individual untuk menentukan koefisien regresi yang bernilai 0 (Atmaja, 2009:115). Hipotesis dari uji † sebagai berikut :

$\mathrm{H}_{0}=\beta=0$, artinya tidak terdapat pengaruh signifikan antara variabel dependen dan independen.
$H_{1}=\beta \neq 0$, terdapat pengaruh signifikan antara variabel dependen dan independen.

Kriteria penerimaan dan penolakan $\mathrm{H}_{0}$ maupun $H_{1}$ yaitu dengan melihat nilai signifikansi. Jika signifikansi $<5 \%$ maka $\mathrm{H}_{0}$ ditolak dan $\mathrm{H}_{1}$ diterima. Apabila signifikansi $>5 \%$ maka $\mathrm{H}_{0}$ diterima dan $\mathrm{H}_{1}$ ditolak.

Tabel 6

\begin{tabular}{|l|l|l|l|l|}
\multicolumn{7}{|c|}{} & & $\begin{array}{l}\text { Uji T } \\
\text { Vari- } \\
\text { abel } \\
\text { Inde- } \\
\text { pen- } \\
\text { den }\end{array}$ & $\begin{array}{l}\text { Signifi- } \\
\text { kansi } \\
\text { Hipot- } \\
\text { esis }\end{array}$ & $\begin{array}{l}\text { Kete- } \\
\text { rangan }\end{array}$ \\
\hline EAR & 0,481 & 0,05 & $\begin{array}{l}0,481 \\
0,05\end{array}$ & $\begin{array}{l}\text { Tidak } \\
\text { signifikan }\end{array}$ \\
\hline NPF & 0,001 & 0,05 & $\begin{array}{l}0,001< \\
0,05\end{array}$ & Signifikan \\
\hline FDR & 0,673 & 0,05 & $\begin{array}{l}0,673< \\
0,05\end{array}$ & $\begin{array}{l}\text { Tidak } \\
\text { signifikan }\end{array}$ \\
\hline
\end{tabular}

Sumber: Hasil SPSS 20

Tabel 6 menunjukan variabel EAR dan FDR berpengaruh tidak signifikan terhadap ROA. Variabel NPF berpengaruh signifikan.

\section{Koefisien Determinasi $\left(\mathbf{R}^{2}\right)$}

Tujuan dari perhitungan koefisien determinasi adalah untuk mengetahui seberapa besar variabel independen dapat menjelaskan variabel dependen atau dengan kata lain untuk mengetahui keakuratan hubungan variabel dependen dengan independen.

Pada Tabel 7 koefisien determinasi sebesar 0,383 atau 38,3\%. Angka tersebut menunjukkan bahwa variabel ROA dapat dijelaskan oleh variabel EAR, NPF dan FDR sebesar $38,3 \%$. Besar kontribusi pengaruh EAR, NPF dan FDR terhadap ROA pada Koperasi BMT Nurul Jannah tahun 20122014 yaitu $38,3 \%$, sedangkan sisanya yaitu 
61,7\% dipengaruhi oleh faktor-faktor lain yang tidak dimasukkan dalam penelitian ini.

Tabel 7.

Hasil Koefisien Determinasi Model Summary ${ }^{b}$

\begin{tabular}{l|c|r|r|r|r|}
\hline Model & $\mathrm{R}$ & $\begin{array}{c}\mathrm{R} \\
\text { Square }\end{array}$ & $\begin{array}{c}\text { Adjusted R } \\
\text { Square }\end{array}$ & $\begin{array}{c}\text { Std. Error of } \\
\text { the Estimate }\end{array}$ & $\begin{array}{l}\text { Durbin- } \\
\text { Watson }\end{array}$ \\
\hline 1 &, $619^{\mathrm{a}}$ &, 383 &, 326 &, 136359 & 2,282 \\
\hline
\end{tabular}
a. Predictors: (Constant), X3, X1, X2
b. Dependent Variable: Y
Sumber: Hasil SPSS 20

Pembahasan

Pengaruh EAR, NPF dan FDR secara Simultan terhadap ROA Koperasi BMT Nurul Jannah

Rasio EAR, NPF dan FDR merupakan rasio keuangan bank yang didapat dari laporan keuangan. Rasio keuangan adalah angka yang diperoleh dari hasil perbandingan dari satu pos laporan keuangan dengan pos lainnya yang mempunyai hubungan yang relevan dan signifikan (berarti). Rasio keuangan yang digunakan oleh bank dengan perusahaan nonbank sedikit berbeda. Perbedaannya terletak pada jenis rasio yang digunakan oleh bank lebih banyak karena komponen neraca dan laba rugi bank berbeda dengan perusahaan nonbank (Kasmir, 2013:216).

Fungsi dari rasio keuangan yaitu digunakan untuk mengevaluasi kondisi keuangan dan kinerja perusahaan dari tahun ke tahun. Sehingga akan terlihat perkembangan kondisi keuangan perusahaan yang bersangkutan (Kasmir, 2013:104).
Salah satu indikator ukuran kinerja keuangan yaitu ROA. Semakin tinggi ROA menunjukkan semakin baik kinerja BMT karena tingkat pengembalian atau return semakin besar.

Hasil dari rasio kevangan akan tercermin kelemahan dan kekuatan yang dimiliki perusahaan, sehingga kelemahankelemahan tersebut akan diperbaiki dan kekuatan perusahaan akan terus ditingkatkan. Sehingga hal ini akan mencerminkan kondisi serta kinerja (Kasmir, 2013:104).

Apabila rasio keuangan suatu bank baik maka hal ini juga mencerminkan kinerja yang baik pula pada bank tersebut. Kinerja yang baik ditandai dengan tingginya ROA.

\section{Pengaruh EAR terhadap ROA Koperasi BMT}

\section{Nurul Jannah}

$$
\text { Equity to Total Assets Ratio }
$$

menunjukkan besarnya modal sendiri yang digunakan untuk mendanai seluruh aktiva perusahaan (Kurnia, 2012). Variabel EAR berpengaruh tidak signifikan terhadap ROA Koperasi BMT Nurul Jannah Gresik. Hal ini dikarenakan porsi modal sendiri yang digunakan untuk pembiayaan hanya sedikit apabila dibandingkan dengan porsi dana pihak ketiga yang digunakan untuk pembiayaan.

Modal sendiri Koperasi BMT Nurul Jannah Gresik terdiri dari simpanan pokok, simpanan wajib, hibah serta cadangan. Simpanan pokok dan wajib yang berasal dari anggota akan dikembalikan lagi 
apabila anggota kelvar dari keanggotaan koperasi (Tohar, 2000:19). Maka koperasi harus bertanggung jawab akan harta yang diinvestasikan oleh anggota. Hal ini dijelaskan pada Surat AlIsra' ayat 26.

\section{Pengaruh NPF terhadap ROA Koperasi BMT Nurul Jannah}

"Non Performing Financing adalah rasio yang digunakan untuk mengukur kemampuan manajemen bank dalam mengelola kredit bermasalah" (Manikam, 2013:10). Hasil penelitian menunjukkan bahwa NPF mempunyai pengaruh signifikan terhadap ROA. Semakin rendah NPF maka BMT semakin bisa mengelola pembiayaan dengan baik, sehingga hal ini akan berdampak pada profitabilitas yang akan meningkat. Sebaliknya, apabila semakin tinggi NPF, akan menyebabkan profitabilitas menurun. Hal ini dikarenakan penyaluran pembiayaan tidak didukung oleh kualitas pembiayaan yang baik. Sehingga semakin tinggi pembiayaan yang disalurkan oleh Koperasi BMT Nurul Jannah, semakin tinggi pula pembiayaan bermasalah BMT ini. Hasil penelitian ini mendukung penelitian Manikam (2013:8) yang mengatakan bahwa Rasio Non Performing Loan (NPL) memiliki pengaruh signifikan terhadap ROA.

Variabel NPF menunjukkan prinsip kehati-hatian yang dilakukan oleh BMT. Hukum Islam banyak menjelaskan tentang prinsip kehati-hatian atau prinsip berusaha yang berdasarkan etika Islam yang diterapkan oleh perbankan syariah. Ketentuan tersebut diatur dalam Surat AlMaidah ayat 49 (Darwini, 2005:5).

Pengaruh FDR terhadap ROA Koperasi BMT Nurul Jannah

Hasil penelitian menunjukkan bahwa variabel FDR memiliki pengaruh tidak signifikan terhadap ROA. Hal ini dapat disebabkan oleh berbagai hal.

Semakin meningkatnya FDR Koperasi BMT Nurul Jannah, seharusnya diikuti pula kenaikan pada ROA, namun pada penelitian ini ditemukan fakta lain yaitu kenaikan FDR tidak berpengaruh signifikan terhadap ROA. Hal ini dikarenakan terdapat variabel pengganggu. Variabel pengganggu tersebut yaitu NPF.

Hasil penelitian ini didukung oleh Suryani (2011:26) yang mengatakan bahwa tidak adanya pengaruh yang signifikan pada FDR terhadap ROA.

Dana pihak ketiga yang didapat dari masyarakat, harus di olah sebaik mungkin, karena dana pihak ketiga tersebut berarti amanah yang diberikan oleh masyarakat kepada bank, BMT maupun lembaga lainnya. Hal ini sesuai dengan yang tercantum dalam Al-Qur'an Surat Al-Anfal ayat 27.

\section{SIMPULAN}

\section{Simpulan}

Berdasarkan hasil penelitian mengenai pengaruh Equity to Total Assets Ratio, Non Performing Financing dan Financing to Deposit Ratio terhadap Return on Assets Ratio pada Koperasi BMT Nurul Jannah 
tahun 2012-2014, dapat ditarik kesimpulan sebagai berikut :

1. Berdasarkan hasil uji F statistik (secara simultan) dengan tingkat error (a) sebesar 0,05, menunjukkan bahwa secara statistik dapat disimpulkan bahwa EAR, NPF dan FDR secara bersama-sama berpengaruh signifikan terhadap ROA Koperasi BMT Nurul Jannah tahun 2012-2014.

2. Berdasarkan hasil uji t statistik (secara parsial) menunjukkan bahwa Equity to Total Asets Ratio (EAR) berpengaruh tidak signifikan terhadap Return on Assets (ROA).

3. Berdasarkan hasil uji t statistik (secara parsial) menunjukkan bahwa Non Performing Financing (NPF) berpengaruh signifikan terhadap Return on Assets (ROA).

4. Berdasarkan hasil uji † statistik (secara parsial) menunjukkan bahwa Financing to Deposit Ratio (FDR) berpengaruh tidak signifikan terhadap Return on Assets (ROA).

Berdasarkan simpulan diatas, maka saran yang diberikan adalah agar BMT lebih memperhatikan faktor-faktor yang dapat mempengaruhi profitabilitas BMT, seperti rasio NPF yang menunjukkan pembiayaan bermasalah. Baitul Maal Wattamwil diharapkan lebih memperhatikan pembiayaan bermasalah yang tergolong dalam pembiayaan kurang lancar, diragukan dan macet, agar profitabilitas BMT tidak menurun. Koperasi bisa meningkatkan kualitas pembiayaan dengan cara melakukan analisis kredit 5C, melakukan pengawasan terhadap nasabah pembiayaan.

\section{DAFTAR PUSTAKA}

Afandi, Pandi. 2014. Analisis Kinerja Keuangan untuk Mengukur Kesehatan Keuangan Koperasi KSU BMT Arafah Kecamatan Bancak Kabupaten Semarang, (Online), Vol.7 No.13, (http://jurnal.stieama.ac.id/index., diakses pada 2 Februari 2015).

Arifin, Johar. 2008. Statistik Bisnis Terapan dengan Microsoft Excel 2007. Jakarta: PT Elex Media Komputindo.

Atmaja, Lukas Setia. 2009. Statistika untuk Bisnis dan Ekonomi. Yogyakarta : CV. Andi Offset.

Candraeni, I Gusti Ayu Mas. 2013. Pengaruh Receivable Turnover, Debt to Equity Ratio, Equity to Total Assets Ratio pada Return on Investment, (Online), Volume 5 No. (http://ojs.unud.ac.id/index., diakses pada 13 Desember 2014).

Darwini, T. 2005. Urgensi Pengaturan Prinsip Kehati-hatian (Prudent Banking Principle) dalam Pengelolaan Bank, (Online), Volume 10 No. 2, http://download.portalgaruda.org/arti cle.php, diakses pada 17 April 2015).

Faisol, Ahmad. 2007. Analisis Kinerja Keuangan Bank pada Bank Muamalat Indonesia Tbk, (Online), Volume 3 No. 2 , http://www.academia.edu/, diakses pada 2 Februaru 2015). 
Gill, James O dan Chaton. 2005. Memahami Laporan Kevangan : Memanfaatkan Informasi Kevangan untuk Mengendalikan Bisnis Anda. Jakarta : PPM.

Hapsari, Endah. 26 Oktober, 2013. RI Terbaik di Dunia dalam Keuangan Mikro Syariah. Republika Online.

Hermawan, Asep. 2005. Penelitian Bisnis Paradigma Kuantitatif. Jakarta : Grasindo.

Jumingan. 2009. Analisis Laporan Keuangan. Jakarta: Bumi Aksara.

Kurnia, Indra. 2012. Analisis Pengaruh Bopo, Equity To Total Assets Ratio, Loan To Assets Ratio dan Firm Size Terhadap Kinerja Keuangan (Studi Kasus Pada Bank Umum Konvensional Go Public yang Listed di BEI tahun 2008 sampai dengan tahun 2011), (Online), Volume 1 No. 2, (http://eprints.undip.ac.id, diakses 11 September 2014).

Leon, Boy dan Sony Ericson. 2005. Manajemen Aktiva Pasiva Bank Nondevisa. Jakarta: Grasindo Manikam, Johar. 2013. Analisis Pengaruh Capital Adequacy Ratio (CAR), Net Interest Margin (NIM), Loan To Deposit Ratio (LDR), Non Performing Loan (NPL) dan BOPO terhadap Profitabilitas Bank Persero di Indonesia Periode 2005-2012, (Online), Volume 2 No. 4, (http://ejournal-sl.undip.ac.id, diakses 11 Desember 2014).

Muhammad. 2002. Manajemen Bank Syariah. Yogyakarta : UPP AMP YPKN.
Rafelia, Thyas dan Moh. Didik Ardiyanto. 2013. Pengaruh CAR, FDR, NPF, dan BOPO terhadap ROE Bank Syariah Mandiri Periode Desember 2008 Agustus 2012, (Online), Volume 1 , Nomor 1, (http://ejournalsl.undip.ac.id, diakses pada 4 September 2014).

Sholihin, Ahmad Ifham. 2010. Buku Pintar Ekonomi Syariah. Jakarta : Gramedia Pustaka Utama.

Siegel, Sidney. $1986 . \quad$ Statistik Nonparametrik untuk IImu-ilmu Sosial. Jakarta : Gramedia.

Sitio, Arifin dan Halomoan Tamba. 2001. Koperasi Teori dan Praktik. Jakarta : Erlanggan.

Sujarweni, V. Wiratma. 2014. SPSS untuk Penelitian. Yogyakarta : Pustaka Baru Press.

Sudarsono, Heri. 2003. Bank dan Lembaga Kevangan Syariah. Yogyakarta : Ekonisia.

Soegoto, Eddy Soeryanto. 2008. Marketing Research The Smart Way to Solve a Problem. Jakarta : Elex Media Komputindo.

Supranto. 2000. Statistik : Teori dan Aplikasi. Jakarta : Erlangga.

Suryani. 2011. Analisis Pengaruh Financing to Deposit Ratio (FDR) terhadap Profitabilitas Perbankan Syariah di Indonesia, (Online), Volume 19 No. 1, (http://jurnal.walisongo.ac.id, diakses pada 10 September 2014).

Tohar. 2000. Permodalan dan Perkreditan Koperasi. Yogykarta : Kanisius. 
Wibowo, Edhi Satriyo. 2013. Analisis Pengaruh Suku Bunga, Inflasi, CAR, BOPO, NPF terhadap Profitabilitas Bank Syariah, (Online), (http://ejournal1s1.undip.ac.id,diakses pada 19 Maret 2015). 